\title{
Energy consumption in the UK food chill chain - primary chilling
}

\author{
Mark J. Swain, Judith A. Evans and Stephen J. James \\ Food Refrigeration and Process Engineering Research Centre (FRPERC), University of Bristol, Churchill Building, \\ Langford, Bristol BS40 5DU, UK. Tel.+44 (0)117938 9310.Fax+44(0)1179289314 E-mail m.j.swain@bristol.ac.uk
}

\begin{abstract}
There is increasing pressure on governments and industries to make significant reductions in carbon emissions. In the UK, $11 \%$ of electricity is consumed by the food industry and in some sectors a substantial portion of site energy, up to $90 \%$, is consumed by refrigeration systems. The aim of this work was to: identify the major primary chilling energy requirements in the UK; calculate or make a best estimate of their efficiency; and determine which chilling processes have the highest energy saving potential. In terms of the heat energy to be extracted during the primary chilling process, the six most important categories in rank order were milk (532 $\mathrm{GWh} /$ year), meat (114 GWh/year), potatoes (59 GWh/year), other vegetables (36 GWh/year), fish (6.5 GWh/ year) and fruit $(5.9 \mathrm{GWh} /$ year). There is little published data on the measured energy consumption of commercial primary chilling processes in the UK or that is directly applicable to the UK. From the data that is available, the energy efficiency (useful heat extracted from material/measured electrical energy used) varies from 0.138 to 5.337 , with cooling of milk being far more efficient than that of the next two most important categories, meat and potatoes. Using the best of existing technologies it is estimated that $154 \mathrm{GWh}$ could be saved per year in potato cooling, $128 \mathrm{GWh}$ in milk and between 51 and $80 \mathrm{GWh}$ in the cooling of carcass meat. Savings in other commodity areas are likely to be more than an order of magnitude less.
\end{abstract}

Keywords: energy, food refrigeration, cold chain, post harvest, post slaughter

\section{Introduction}

With the rising concern over climate change, global warming and the recent sharp increases in energy costs, there is increasing pressure on government and industry to make significant reductions in carbon emissions. This has resulted in greater efforts to focus on energy consumption and ways to reduce it to sustainable levels. Worldwide, it is estimated that $15 \%$ of the electricity consumed is used for refrigeration, and Mattarolo (1990) estimates that 40\% of food requires refrigeration. In the UK, $11 \%$ of electricity is consumed by the food industry (Department for Business Enterprise and Regulatory Reform (BERR) 2005). However, detailed estimates of what proportion of this is used for refrigeration processes are less clear and often contradictory. Efforts to determine how much energy is used in each sector of the food industry for refrigeration is often hampered by the apparent lack of measured data and limited availability of process throughput data (Swain 2006).

The cold chain is vital in ensuring the safety, organoleptic quality, nutritional content and market value of per-

Food Manufacturing Efficiency 2 (2) 1-9. DOI: 10.1616/1750-2683.00xx Submitted 2 September 2008. Accepted for publication 20 November 2008. ISSN 1750-2683 C IFIS Publishing 2009. All Rights Reserved ishable foodstuffs from harvest to consumer. Due to the current concerns over climate change and increasing energy prices, it is now appropriate to examine whether current technologies and practices in use throughout the cold chain are the most efficient and sustainable.

There are many publications (International Institute of Refrigeration 2000; James and James 2004, 2006; ASHRAE 2006) that cover the range of refrigeration systems used to chill foods and others more specific to red meat (James and James 2002), poultry (James 2004), fruits and vegetables (Aked 2005), fish (Jul 1985) and dairy (Lascu 1976). Table 1 provides a summary of the primary chilling methods used for each major raw material.

This study focuses on the first stage of the food chill chain and aims to determine the energy required for refrigeration of raw food materials immediately post harvest or slaughter in the UK and to identify the main products where the potential for saving energy is the greatest.

The energy consumption of a refrigeration system for cooling food is dependent on a number of factors not least the energy that is required to be removed from the food itself to reduce its temperature from its initial post harvest/slaughter temperature to its desired storage temperature; the product heat load. In addition, the heat load seen by a refrigeration system is made up of the heat from the 
Table 1. Raw material and primary chilling methods used

\begin{tabular}{ll}
\hline Raw material & Primary chilling method(s) $\left({ }^{\circ} \mathrm{C}\right)$ \\
\hline Meat & Forced air chilling \\
Fish & Packing in ice \\
& Chilled sea water \\
& Ice/water slurry \\
Apples & Forced air chilling (rapid) \\
& Room cooling (slow) \\
& Hydrocooling \\
Strawberries & Forced air chilling \\
Carrots and turnips & Forced air chilling \\
& Hydrocooling \\
Onions & Drying/Forced air \\
& chilling (in store) \\
Cabbages and other brassicas & Forced air chilling \\
Cauliflowers and broccoli & Forced air chilling \\
Lettuce and chicory & Icing (US) \\
Peas, green & Hydrocooling \\
Tomatoes & Vacuum cooling \\
Potatoes & Forced air chilling \\
Milk & Hydrocooling (freezing) \\
\hline
\end{tabular}

surroundings (e.g. transmission through chillroom walls, ceiling and floor), air infiltration/ingress (e.g. through open doors, faulty seals), packaging/containers, ancillary equipment (e.g. motors, lights, fans and pumps) and people. In primary cooling systems, the majority of the total heat load should be the product load since the purpose of a primary chilling system is to extract this load. The extraction of this energy from the food must be carried out in the most energy efficient manner.

The product heat load is dependent on the initial temperature of the product (at harvest or slaughter), the final temperature to which the product is required to be cooled prior to storage, the mass of the product that is being cooled. In some raw products (fruits and vegetables), heat from respiration is also part of the heat load but this has been assumed to be insignificant for the purposes of this study.

\section{Refrigeration requirement and efficiency}

The aim of this work was to:

- Identify the major primary chilling energy requirements in the UK

- Calculate or make a best estimate of their efficiency

- Determine which chilling processes had the highest energy saving potential.

To achieve these aims, all the available data on the annual volume (tonnes) of each of the major raw food materials produced in the UK has been collated. The amount of thermal energy that has to be removed post harvest or slaughter to cool it to its recommended storage temperature per year, i.e. the temperature at which it enters the chill chain has then been calculated. Available data on the amount of energy used in existing chilling systems has then been used to estimate the current efficiency of chilling systems and the processes with the greatest energy saving potential identified.

\subsection{Annual chilling requirements in the UK}

\subsubsection{Red and white meat}

Red meat - the major red meat species are beef/veal, pork and lamb with a combined annual production of approaching 1.8 million tonnes in 2005 (Figure 1). The total annual UK production of horse, goat and other red meats is only about 4 thousand tonnes/year and is not considered in this study.

White meat - chicken is by far the major meat under this category with an annual UK production of 1.3 million tonnes/year, followed by turkey with 206 thousand tonnes/ year and duck with approaching 42 thousand tonnes/year. The combined annual production of goose and guinea fowl meat is less than 3 thousand tonnes/year. The total annual production figure for game meat is 5 thousand tonnes/year and, therefore, only has a very small impact on the amount of energy used for meat refrigeration in total.

\subsubsection{Fish}

One of the most important pre-requisites for obtaining an optimal quality of fish is rapid chilling after catching and storage at a temperature of $0{ }^{\circ} \mathrm{C}$ (Hanusardottir et al. 1985). The total weight of fish landed in the UK in 2005 (including shell fish and freshwater fish) was approximately 824 thousand tonnes (Figure 2). Large pelagic fish

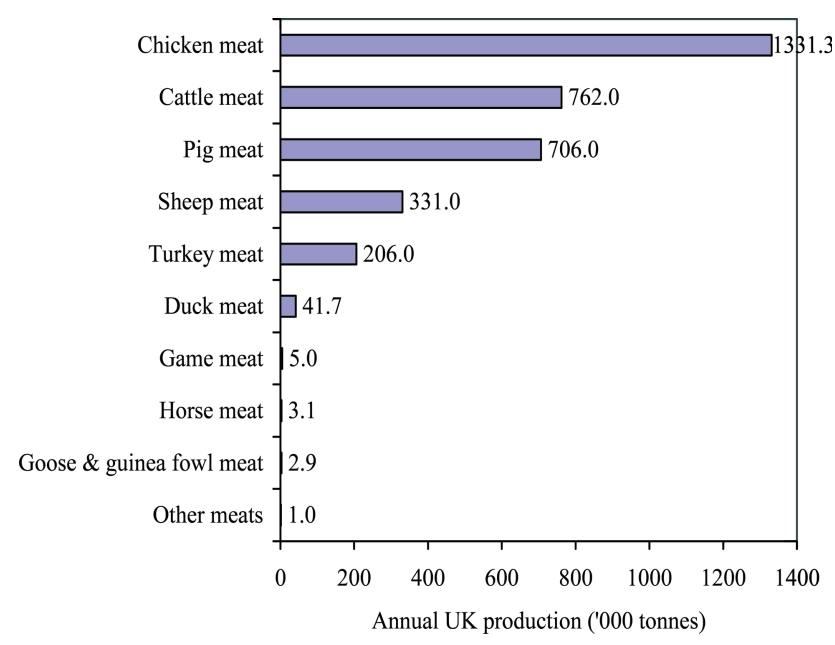

Figure 1. Annual UK production of meat in 2005 in thousands of tonnes (FAOSTAT 2007). 


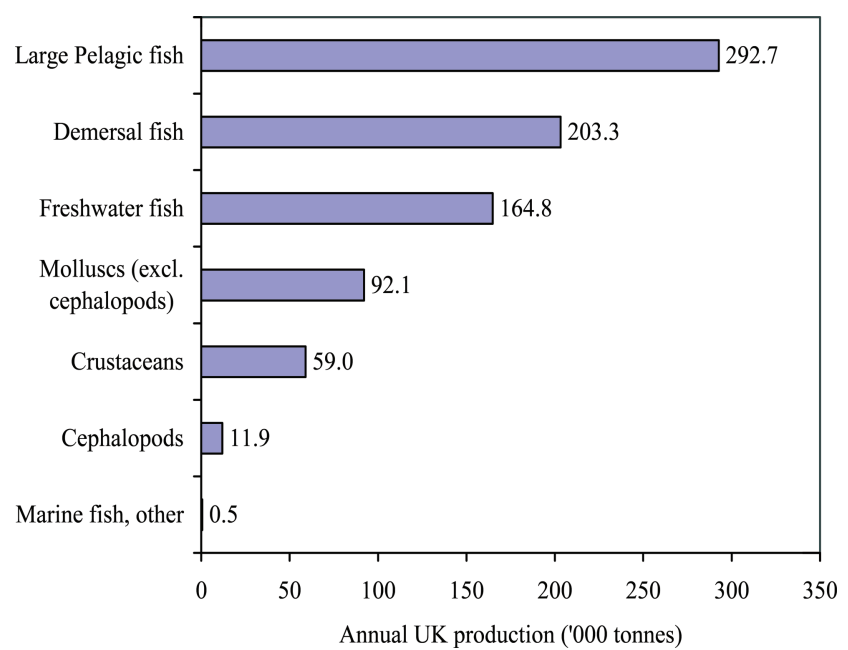

Figure 2. Annual UK production of fish in 2005 in thousands of tonnes (FAOSTAT 2007).

(including mackerel and herring) and demersal fish (including cod and haddock) accounted for over half of the total weight of fish landed with a combined figure of almost 496 thousand tonnes.

\subsubsection{Fruit}

The total tonnage of fruit that would require primary chilling in the UK in 2005 was 359 thousand tonnes. Apples made up more than $60 \%$ (218 thousand tonnes/year) of this total followed by strawberries (62.6 thousand tonnes/ year) (Figure 3).

\subsubsection{Vegetables and salad crops}

In 2005, the UK production of potatoes was over 5.8 million tonnes, which made up almost $68 \%$ of the tonnage of

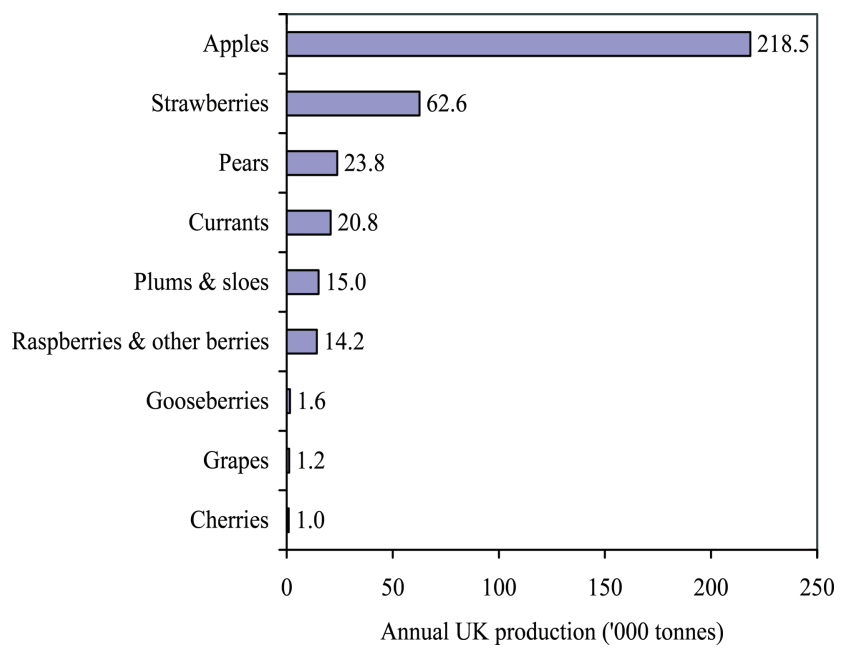

Figure 3. Annual UK production of fruit in 2005 in thousands of tonnes (FAOSTAT 2007). vegetables and salad crops chilled. The next most important category, carrots and turnips, made up less than $10 \%$ of the total (Figure 4). Potatoes are traditionally stored in bulk in large storage buildings, which are not always refrigerated. However, there is a continuing trend towards more potatoes being stored refrigerated to satisfy the requirements of supermarkets.

\subsubsection{Milk}

The UK is the third largest producer of milk in Europe with an annual production of whole fresh cows' milk of 14.6 million tonnes in 2005. Of this, just over 14 million tonnes was collected for use by dairies with approximately half going on to be consumed as milk (49\%) and half for processing into dairy products, mainly cheese $(27 \%)$.

\subsubsection{Cereals and grains}

As cereals and grains are cooled post harvest by ventilating with ambient air (not refrigerated), they are not considered within this study.

\subsubsection{Overall production}

Overall milk is chilled in substantially larger tonnages than any other single primary food material or material category in the UK (Figure 5). Potatoes, which are the next largest single primary food, account for less than $40 \%$ of the milk tonnage. However, this is still substantially larger than any other raw material category.

\subsection{Energy to be extracted}

The energy required to cool each of the raw food materials was calculated using the overall weight of annual UK production multiplied by the enthalpy change required to reduce the temperature post harvest/slaughter to its recommended storage temperature. For each raw material selected, Table 2 provides details of the initial temperature $\left({ }^{\circ} \mathrm{C}\right)$, final temperature $\left({ }^{\circ} \mathrm{C}\right)$ and the calculated enthalpy change $\left(\mathrm{kJ} \mathrm{kg}^{-1}\right)$. To compile Table 2, the following assumptions were made concerning the initial and final average temperatures of the selected primary food materials. Red and white meat has been assumed to start off close to the body temperature of the live animal $\left(40^{\circ} \mathrm{C}\right)$ and be cooled to $3^{\circ} \mathrm{C}$. The legal requirement in the UK is for red meat to be chilled to a maximum core temperature of $7^{\circ} \mathrm{C}$ and poultry to $3^{\circ} \mathrm{C}$. To achieve this requirement the average temperature of the chilled carcass will be close to or slightly below $3^{\circ} \mathrm{C}$. Fish have been assumed to start at $10^{\circ} \mathrm{C}$ (average water temperature around the UK) and be cooled to $0^{\circ} \mathrm{C}$. Current legislation requires fish to be stored at the temperature of melting ice $\left(0^{\circ} \mathrm{C}\right)$. After milking the temperature of milk is between 35 and $37^{\circ} \mathrm{C}$ 


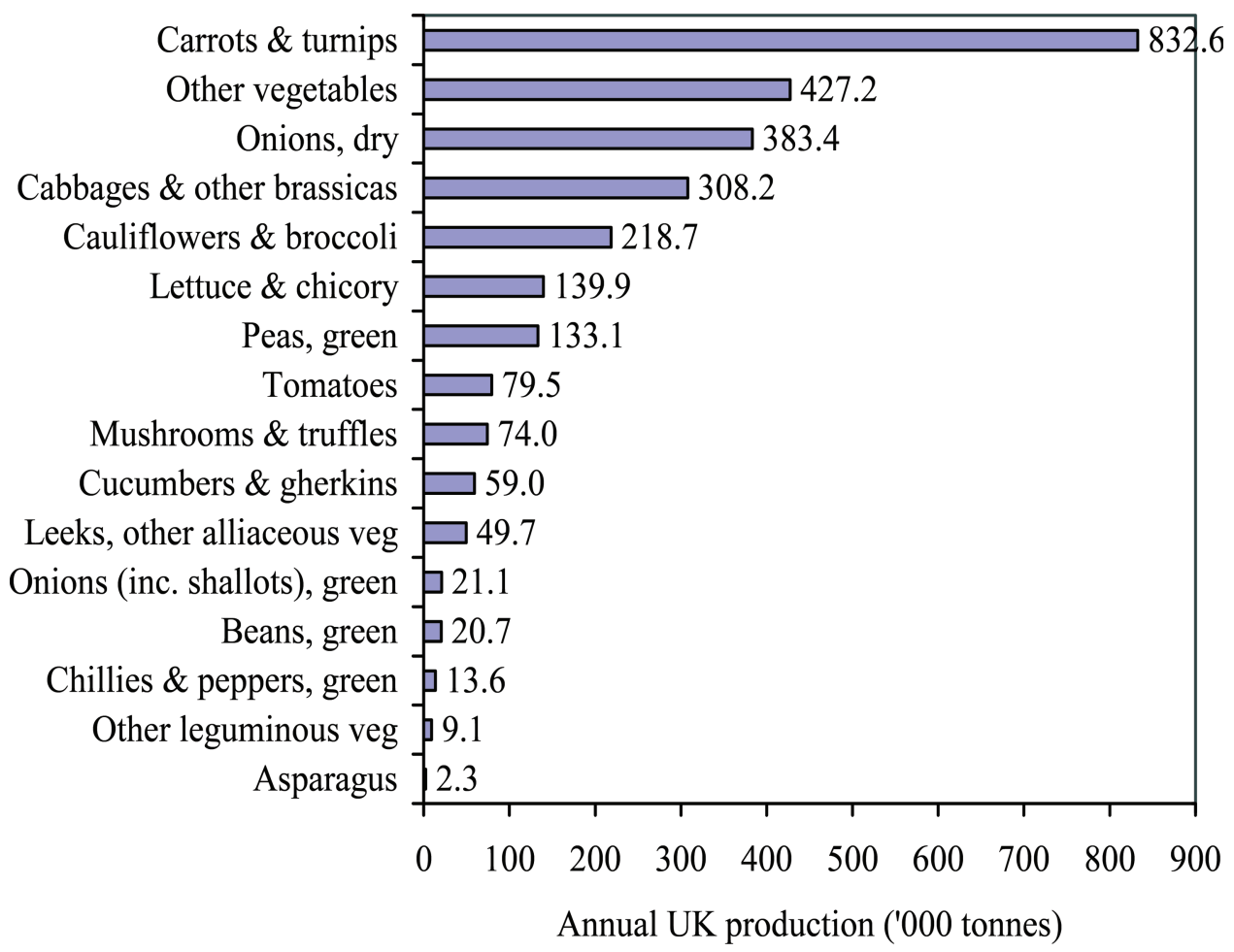

Figure 4. Annual UK production of vegetables in 2005 in thousands of tonnes (FAOSTAT 2007).

and is typically cooled to $4^{\circ} \mathrm{C}$ prior to collection by insulated road tankers. Although codes of practice allow temperatures higher than this (up to $8^{\circ} \mathrm{C}$ for milk collected daily, up to $6^{\circ} \mathrm{C}$ if longer), the requirements of the milk purchasers specifications often require that milk is cooled to $4{ }^{\circ} \mathrm{C}$ to avoid penalty payments. Apples, strawberries and tomatoes have been assumed to be picked in summer

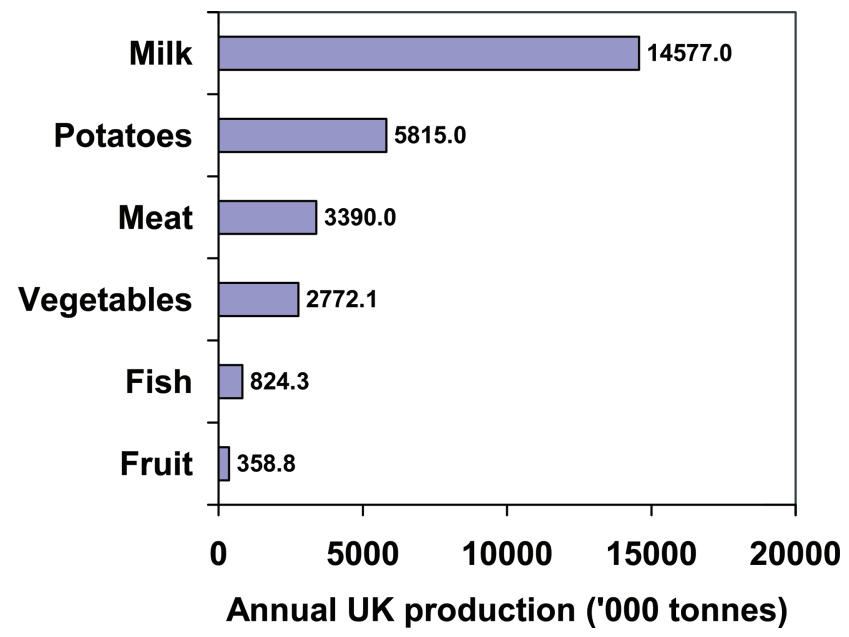

Figure 5. Annual UK production of selected primary food materials in 2005 in thousands of tones.
Table 2. Initial and final temperature and enthalpy change per $\mathrm{kg}$ to reduce average temperature of selected primary food materials from initial to final temperature

\begin{tabular}{lccc}
\hline Raw material & $\begin{array}{c}\text { Initial } \\
\text { temperature } \\
\left({ }^{\circ} \mathrm{C}\right)\end{array}$ & $\begin{array}{c}\text { Final } \\
\text { temperature } \\
\left({ }^{\circ} \mathrm{C}\right)\end{array}$ & $\begin{array}{c}\text { Enthalpy } \\
\text { change } \\
\left(\mathrm{kJ} \mathrm{kg}^{-1}\right)\end{array}$ \\
\hline Chicken meat & 40 & 3 & 125.6 \\
Cattle meat & 40 & 3 & 118.7 \\
Pig meat & 40 & 3 & 112.4 \\
Sheep meat & 40 & 3 & 125.0 \\
Turkey meat & 40 & 3 & 129.1 \\
Duck meat & 40 & 3 & 110.9 \\
Large Pelagic fish & 10 & 0 & 34.0 \\
Demersal fish & 10 & 0 & 37.3 \\
Freshwater fish & 10 & 0 & 35.4 \\
Apples & 20 & 0 & 75.3 \\
Strawberries & 20 & 0 & 78.6 \\
Carrots and turnips & 15 & 0 & 57.2 \\
Onions & 15 & 0 & 57.7 \\
Cabbages and other & 15 & 0 & 58.2 \\
$\quad$ brassicas & & & \\
Cauliflowers \& broccoli & 15 & 0 & 59.5 \\
Lettuce and chicory & 15 & 0 & 59.5 \\
Peas, green & 15 & 0 & 51.4 \\
Tomatoes & 20 & 8 & 60.8 \\
Potatoes & 15 & 5 & 36.5 \\
Milk & 37 & 3 & 131.3 \\
& & & \\
\hline
\end{tabular}




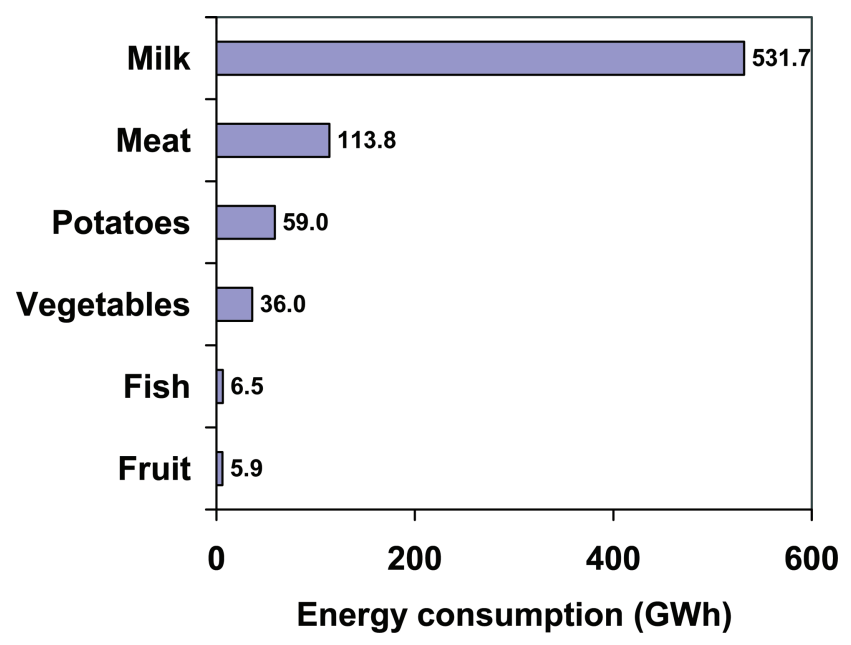

Figure 6. Estimated annual heat energy that needs to be extracted to cool selected major raw food materials post harvest/slaughter.

at an average temperature of $20^{\circ} \mathrm{C}$ and root crops and other vegetables which are harvested throughout the year $15^{\circ} \mathrm{C}$. The fruits and vegetables are assumed to be cooled to their optimum storage temperatures which range from 0 to $8^{\circ} \mathrm{C}$.

To calculate the enthalpy that would have to be removed to reduce the temperature of the product by the desired amount, compositional data for an average material of each type was obtained from the USDA Nutrient Database (Anon 2006). Using this data, an FRPERC proprietary program (FoodProp), which is based on the COSTHERM equations (Miles et al. 1983) relating thermal properties to a foods composition, was used to calculate the enthalpy change per $\mathrm{kg}$.

Summing the annual production $\times$ enthalpy figures for each raw material the total amount of energy that had to be extracted each year was then calculated (Figure 6). In the UK, milk is the raw material that requires the most cooling with an estimated energy value at least 2.5 times more than all the other major materials added together and over 4.5 times more than all types of meat combined. In addition to milk and meat the primary chilling of vegetables, especially potatoes, requires the extraction of substantial quantities of heat.

\subsection{Efficiency of current practices}

To be able to calculate the energy efficiency of current primary chilling processes data is required on the measured energy consumption of industrial systems for a known throughput of the raw material being chilled. The authors have been able to locate very few publications that contain both measured energy and throughput data. However, five publications have been located that provide some relevant data on milk, potatoes and meat which are three of the key primary raw materials in terms of a high primary chilling energy requirement.

Two publications provide actual on farm energy use for milk refrigeration that can be correlated to throughput. The UK Milk Development Council (1995) reported on the measured energy consumption of different types and configurations of on farm milk coolers, which provides a basis for estimations of energy required to cool the UK milk production. The data indicated that the energy used by the least efficient (old ice bank tank) milk cooling system $(21.6 \mathrm{kWh} /$ tonne $)$ was almost twice that of the most efficient (direct expansion (DX) tank with new scroll compressor, $11.2 \mathrm{kWh} /$ tonne). If the effect of adding plate heat exchangers is taken into account then this difference is even greater. In a US study, Legett et al. (1997) reports values for the average unit energy use to cool milk on the farm from 4.84 to $11.66 \mathrm{kWh} /$ tonne for different scenarios. Using these data the measured energy consumption per $\mathrm{kg}$ of milk cooled would vary from 24.6 to $77.8 \mathrm{~kJ}$. The efficiency (ratio of useful heat energy removed to electrical energy consumed) of a milk cooling process can therefore vary from 5.337 to 1.668 (Table 3).

Devres and Bishop (1992) provide monthly energy consumption data measured at a UK potato storage facility over a complete storage period from September to June. Using this data, the energy efficiency over the total storage period is 0.14 (Table 3). This includes energy required to both initially cool and subsequently store the potatoes over the whole storage period. If it is assumed that all the product load is removed in the initial two months as judged by the levelling out of the monthly energy data stated, then it is estimated that the efficiency rises to 0.31 .

Two sets of data are available for the primary chilling of meat carcasses. One applies to beef and the other to pork. Gigiel and Collett (1989) provide measured specific energy consumption data for primary chilling of beef carcasses in 14 different chilling systems in the UK. Values range from $68.8 \mathrm{~kJ} \mathrm{~kg}^{-1}$ for the most efficient chiller to $187 \mathrm{~kJ} \mathrm{~kg}^{-1}$ for the least efficient, with a mean value of $122.5 \mathrm{~kJ} \mathrm{~kg}^{-1}$. The efficiency (ratio of useful heat energy removed to electrical energy consumed) of a beef cooling process can therefore vary from 1.7 to 0.63 (Table 3 ). Collett and Gigiel (1986) provide measured specific energy consumption data for primary chilling of pork carcasses in the UK. Values range from $89 \mathrm{~kJ} \mathrm{~kg}^{-1}$ for the most efficient chiller to $258 \mathrm{~kJ} \mathrm{~kg}^{-1}$ for least efficient with a mean value of $153 \mathrm{~kJ} \mathrm{~kg}^{-1}$. The efficiency (ratio of useful heat energy removed to electrical energy consumed) of a pork cooling process can, therefore, vary from 1.3 to 0.44 (Table 3).

The values of measured energy consumption for fish in Table 3 are based on data provided in Myers (1981) for 
Table 3. Useful heat energy extracted, measured electrical energy consumed and maximum and minimum ratio (useful:measured) for different primary raw materials

\begin{tabular}{|c|c|c|c|c|}
\hline \multirow[b]{2}{*}{ Raw material } & \multirow{2}{*}{$\begin{array}{c}\text { Useful heat } \\
\text { extracted }\left(\mathrm{kJ} \mathrm{kg}^{-1}\right)\end{array}$} & \multirow{2}{*}{$\begin{array}{c}\text { Measured energy } \\
\text { consumption }\left(\mathrm{kJ} \mathrm{kg}^{-1}\right)\end{array}$} & \multicolumn{2}{|c|}{ Ratio useful to measured } \\
\hline & & & Maximum & Minimum \\
\hline Chicken meat & 125.6 & - & & \\
\hline Cattle meat & 118.7 & $68.8-187^{1}$ & 1.725 & 0.634 \\
\hline Pig meat & 112.4 & $89-258^{2}$ & 1.263 & 0.436 \\
\hline Sheep meat & 125.0 & - & & \\
\hline Turkey meat & 129.1 & - & & \\
\hline Duck meat & 110.9 & - & & \\
\hline Large Pelagic fish & 34.0 & $18.3-21.9^{3}$ & 1.86 & 1.55 \\
\hline Demersal fish & 37.3 & $20.1-24.1^{3}$ & 1.86 & 1.55 \\
\hline Freshwater fish & 35.4 & $19.0-22.8^{3}$ & 1.86 & 1.55 \\
\hline Apples & 75.3 & - & & \\
\hline Strawberries & 78.6 & & & \\
\hline Carrots and turnips & 57.2 & - & & \\
\hline Onions & 57.7 & - & & \\
\hline Cabbages and other brassicas & 58.2 & & & \\
\hline Cauliflowers and broccoli & 59.5 & - & & \\
\hline Lettuce and chicory & 59.5 & - & & \\
\hline Peas, green & 51.4 & - & & \\
\hline Tomatoes & 60.8 & - & & \\
\hline Potatoes & 36.5 & $116.6-265.3^{4}$ & 0.313 & 0.138 \\
\hline Milk & 131.3 & $24.6-77.8^{4,5}$ & 5.337 & 1.688 \\
\hline $\begin{array}{l}{ }^{1} \text { Gigiel and Collett } 1989 \\
{ }^{2} \text { Collett and Gigiel } 1986 \\
{ }^{3} \text { Myers } 1981 \\
{ }^{4} \text { Devres and Bishop } 1992 \\
{ }^{5} \text { Milk Development Council } 1995 \\
{ }^{6} \text { Legett et al. } 1997\end{array}$ & & & & \\
\hline
\end{tabular}

the electrical energy required to produce flake ice using an industrial scale ice making system (50 to $60 \mathrm{kWh} /$ tonne). The mass of ice required to chill each $\mathrm{kg}$ of fish from 10 down to $0^{\circ} \mathrm{C}$ was calculated (assuming that all ice is just melted) using equation (1):

Mass of ice $(\mathrm{kg})=$

Mass of fish $(\mathrm{kg}) \times$ Enthalpy change to cool fish $\left(\mathrm{kJ} \mathrm{kg}^{-1}\right)$ Energy required to convert water toice $\left(\mathrm{kJ} \mathrm{kg}^{-1}\right)$

Approximately $0.1 \mathrm{~kg}$ of ice is required to cool each $\mathrm{kg}$ of fish from 10 to $0^{\circ} \mathrm{C}$. The ratio of useful to 'measured' values in Table 3 for fish are based on an industrial flake ice machine producing this amount of ice per $\mathrm{kg}$ of whole fish. However, in practice more ice is required to compensate for thermal losses from containers and ice handling losses. Myers (1981) states that an ice to fish ratio of 1:2 is commonly used on board fishing vessels in temperate climates, to allow enough ice for initial cooling and storage for voyages up to 18 days. However, in reality ice requirements could vary greatly depending on types of containers and local practices etc. (Zugarramurdi et al. 1995).
In order of energy efficiency current milk cooling can be three times more efficient than primary carcass cooling (5.4 to 1.7). However, the least efficient milk cooling system (efficiency 1.7) has a similar efficiency to that of the best carcass cooler (1.7). The efficiency of fish cooling appears to be similar to that of meat even though a very different cooling method is used. Potato cooling is the least efficient process with a 17 -fold ratio between it and the best milk cooling process $(0.31: 5.3)$ and a 5.5 fold ratio between it and the best carcass cooling system (1.7:0.31).

\section{Energy saving potential}

There are a number of stages in quantifying the potential to save energy in different primary chilling operations. The first stage is a simple technology transfer exercise in which the most energy efficient current industrial process is identified.

With milk and carcass meat, data exists to make a first attempt at calculating the energy reduction potential of a simple technology transfer exercise.

Refrigeration accounts for $20-40 \%$ of the electrical energy consumption of a milking operation (Plemper and 
Stace 2003; Souness 2005). However, no data have been located on the number of each type of system currently used for on-farm cooling of milk in the UK, but if it is assumed that all UK milk production is cooled with equipment having the efficiency of the average between a new ice bank and a standard DX cooling system reported, the annual electrical consumption would be $227 \mathrm{GWh} /$ year. This could be reduced to $163 \mathrm{GWh} /$ year (28\% reduction) if the most efficient DX system reported was used to cool the same UK milk production and could potentially be reduced further if the additional benefits of pre-cooling with plate heat exchangers were to be included. However, there is the potential impact of the additional cooling water to be considered with the latter option.

In a US study, (Legett et al. 1997) reports values for the average unit energy use to cool milk on the farm from 4.84 to $11.66 \mathrm{kWh} /$ tonne for different scenarios. The least efficient was the base system, a DX cooler with a concentric tube well water pre-cooler. The most efficient scenario was the base DX system with the addition of an upgraded two-stage plate heat exchanger, variable speed milk pump to optimize milk flow through the heat exchanger and a glycol chiller with ambient cooling capabilities for the second stage of the heat exchanger. However, the lowest energy consumption could only be achieved if the ambient temperature was below $-7^{\circ} \mathrm{C}$. In addition, unless the ambient temperature was below $0^{\circ} \mathrm{C}$ the glycol chiller was not as efficient as the DX system alone. Energy values as low as $6.82 \mathrm{kWh} /$ tonne could potentially be achieved by the DX system with the plate heat exchanger and variable speed milk pump optimized system alone. If this could be applied to the UK, then the total energy required to cool the annual milk production could be reduced from the $227 \mathrm{GWh} /$ year estimate to $99.4 \mathrm{GWh} /$ year, a reduction of $56 \%$.

The average energy required to cool cattle and pig carcasses is 122.5 and $153 \mathrm{~kJ} \mathrm{~kg}^{-1}$, respectively, whilst the best system required approximately $69 \mathrm{~kJ} \mathrm{~kg}^{-1}$. The overall amount of energy required to cool the 3390000 tonnes of carcass meat produced in the UK per year, based on these means, is, therefore, in the region of 115 to 144 GWh. Using the most energy efficient meat refrigeration system measured in the identified study, this could be reduced to $64 \mathrm{GWh}$ a reduction of between 44 and $56 \%$.

No data has been located to ascertain the average and lowest energy consumptions in the primary chilling of fish. However, as previously discussed five times as much ice, $0.5 \mathrm{~kg}$ ice $/ 1 \mathrm{~kg}$ of fish, as that theoretically required, $0.1 \mathrm{~kg}$ ice $/ 1 \mathrm{~kg}$ of fish, is used in the recommended method. If it is assumed that by using better insulation and improved ice distribution it is possible to reduce the amount of ice required to $0.3 \mathrm{~kg} / \mathrm{kg}$ of fish (still three times that theoretically required), then the total energy required to cool the annual UK fish production could be

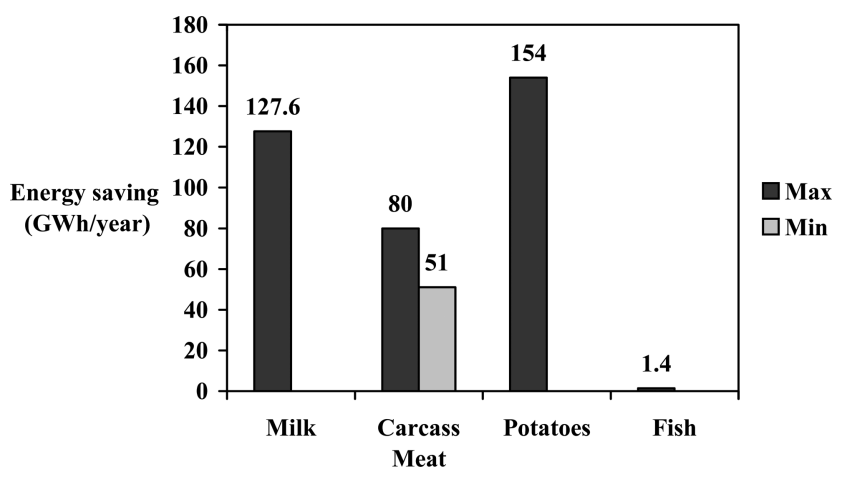

Figure 7. Energy saving potential with existing technology transfer.

reduced from the $3.49 \mathrm{GWh} /$ year estimate to $2.10 \mathrm{GWh} /$ year, a reduction of $40 \%$.

Due to the large throughput of milk the energy saving potential of simple technology transfer in its primary chilling is 48 to $76 \mathrm{GWh}$ more than that from carcass chilling (Figure 7).

A second stage of the process to identify potential to save energy is to see if a simple technology transfer between sectors would be beneficial. The cooling of a liquid product such as milk is a very different process to than of cooling solids such as potatoes and meat carcasses. However, meat carcasses and potatoes are both cooled in air based systems so should it be possible to make potato cooling as efficient as the best of the measured carcass cooling plants i.e improve the efficiency from 0.313 to 1.725 , then this would result in a potential annual saving of $154 \mathrm{GWh}$.

\section{Discussion and conclusion}

The overall objective of the project which this study is part of 'Is to identify and stimulate the development and application of more energy efficient refrigeration technologies and business practices for use throughout the food chain whilst not compromising food safety and quality'. When looking at the potential to save energy in the primary chilling processes we must bear in mind the need to maintain food quality and safety. All primary food-chilling systems were initially developed to increase the high quality distribution life of the raw material.

For a number of raw materials there are standards of legislative requirements on cooling rates or final temperatures. For milk, the European Standard (Comité Européen de Normalisation (CEN) 2002) which deals with the performance for bulk milk coolers on farms defines four classes ( 0 to III) of maximum cooling times to cool any milking from 35 to $4^{\circ} \mathrm{C}$ ranging from 2 to $3.5 \mathrm{~h}$. It also defines the thermal insulation performance stating that 
when milk at $4^{\circ} \mathrm{C}$ is stored at the performance ambient temperature $\left(32^{\circ} \mathrm{C}\right.$ in class $\left.\mathrm{B}\right)$, the mean temperature rise after $12 \mathrm{~h}$ must be a maximum of $+3^{\circ} \mathrm{C}$, without starting the cooler. European Union legislation for red meat requires that for red meat the meat temperature is reduced below $7^{\circ} \mathrm{C}$ before cutting and transportation while poultry meat has to be below $3^{\circ} \mathrm{C}$. No current chilling legislation includes any maximum energy requirements.

Although there are sources of published electrical energy consumption data for the food industry, there are very few that indicate how much of the consumption is due to refrigeration and even fewer that can be relied upon to provide a measure of the energy used for primary cooling of specific materials. Ideally, electrical sub-metering of individual refrigeration systems is required which can be related to volume of product being cooled over a set time period. A number of organisations are no doubt carrying out individual studies to collect the appropriate data, but there is a distinct lack of published data available in the public domain and certainly not enough to accurately determine the full extent of energy used for refrigeration in primary chilling let alone throughout the food industry.

It is important to consider the definition of the system boundaries when interpreting the energy consumption of refrigeration processes. At one extreme only the electrical energy consumed by the compressor motor might be considered and at the other extreme, all of the energy consumption related to the food refrigeration process in total might be included - condenser and evaporator fan motors, defrost heating elements, electric pumps and valves, control panels and also any electrically operated equipment that if the refrigeration process were not in existence would not be required - lights, automatic doors/heaters, auxiliary fan motors, conveyors and process equipment etc. To identify the specific refrigeration processes that have the greatest potential for saving energy, some measure of efficiency needs to be used and clearly defined. In this paper when characterising the efficiency of a refrigeration systems for primary cooling of raw materials post harvest/slaughter the ratio of the heat energy extracted from the food to the total energy consumed in the whole refrigeration system has been calculated.

In terms of the heat energy to be extracted during the primary chilling process the six most important categories in rank order are milk (532 GWh/year), meat (114 GWh/ year), potatoes (59 GWh/year), other vegetables (36 GWh/ year), fish (6.5 GWh/year) and fruit (5.9 GWh/year).

There is little published data on the measured energy consumption of commercial primary chilling processes in the UK or that is directly applicable to the UK. From the data that is available the energy efficiency (useful heat extracted from material/measured electrical energy used) varies from 0.138 to 5.337. Cooling of milk is far more efficient than that of the next two most important categories, meat and potatoes.

Using the best of existing technologies, it is estimated that if applied to the entire UK production, $154 \mathrm{GWh}$ could be saved per year in potato cooling, $128 \mathrm{GWh}$ in milk and between 51 and $80 \mathrm{GWh}$ in the cooling of carcass meat. Savings in other commodity areas are likely to be more than an order of magnitude less.

\section{Acknowledgements}

The authors acknowledge the support of the Defra and input from the collaborating partners, Brunel University, London South Bank University, Sunderland University and the Project Steering Committee and Stakeholders Group.

\section{References}

Aked, J. 2005. Maintaining the post-harvest quality of fruits. In: Jongen, W., editor. Fruit and vegetable processing. CRC press, Cambridge, England.

Anon, 2006. US Department of Agriculture, Agricultural Research Service. USDA Nutrient database for standard reference, release 19. Available at: http://www.ars.usda.gov/nutrientdata.

ASHRAE. 2006. Refrigeration Handbook. 791 Tullie Circle, NE Atlanta, Georgia 30329 USA.

Comité Européen de Normalisation (CEN) 2000. CEN Standard EN 13732:2002. Food processing machinery. Bulk milk coolers on farms. Requirements for construction, performance, suitability for use, safety and hygiene. CEN, Geneva, Switzerland.

Devres, Y. O. and Bishop, C. F. H. 1992. A computer model for weight loss and energy conservation in a fresh produce refrigerated store. Research memorandum 134. Faculty of Engineering Institute of Environmental Engineering, South Bank Polytrchnic, England.

FAOSTAT. 2007. UK annual fish, fruit, meat, milk, starchy roots and vegetable production quantities for the United Kingdom 2005. FAOSTAT, Statistics Division, Food and Agriculture Organisation of the UN. Available at: http://faostat.fao.org/ site/340/DesktopDefault.aspx?PageID=340.

Gigiel, A. J. and Collett, P. 1989. Energy consumption, rate of cooling and weight loss in beef chilling in UK slaughterhouses. Journal of Food Engineering, 10: 255-273.

Collett, P. and Gigiel, A. J. 1986. Energy usage and weight loss in beef and pork chilling. Recent advances and development in the refrigeration of meat by chilling. In: Proceedings of International Institute of Refrigeration: 171-177, Commission C2, Bristol, UK.

Department for Business Enterprise and Regulatory Reform (BERR). 2005. Electricity supply and consumption (DUKES 5.2). Available at: http://stats.berr.gov.uk/energystats/dukes5_2.xls.

Geeson, J. D. 1989. Cooling and storage of fruits and vegetables. In: Proceedings of the Institute of Refrigeration, 1988-1989, $85,1-10$.

Hanusardottir, M., Zachriasen, J. and Mohr, L. 1985. Handling and storage of cod on board inshore boats: 217-222. International Institute of Refrigeration, Aberdeen, UK. ISSN 01511637.

International Institute of Refrigeration (IIR). 2000. Recommendations for chilled storage of perishable produce, IIR, Paris, ISBN 2-913149-09-X. 
James, S. J. and James, C. 2002. Meat Refrigeration: 1-347. Woodhead Publishing, Cambridge, England. ISBN1 855734427.

James, S. J. 2004. Poultry refrigeration. In: Mead, G., editor. Poultry meat processing and quality, Chapter 8: 164-185. Woodhead Publishing, Cambridge, ISBN 1855737272.

James, C. and James, S. J. 2004. Refrigeration and freezing technology (a) equipment. In: Jensen, W. K., Devine, C. and Dikeman, M., editors, Encyclopedia of Meat Sciences: 11441150. Academic Press, Elsevier Science. ISBN 0-12-464970-X.

James, S. J. and James, C. Refrigeration, storage and transport of chilled foods. In: Brown, M., editor, Chilled Foods a Comprehensive Guide, Chapter 3, $3^{\text {rd }}$ Edition. Woodhead Publish-

AQ5 ing, Cambridge, in press.

James, S. J. 2006. Principles of food refrigeration and freezing. In: Hui, Y. H., editor, Handbook of food science, technology, and engineering, Chapter 112: 1-15. Taylor and Francis LLC CRC (3).

Jul, M. 1985. Chilling and freezing fishery products; changes in views and usage. In: Storage lives of chilled and frozen fish and fish products. International Institute of Refrigeration, Commissions C2 \& D3, Aberdeen, UK.

Lascu, G. 1976. Milk and milk products. In: Ciobanu, A., Lascu, G., Bercescu, V. and Nicolescu, L., editors, Cooling technology for the food industry, Chapter 11: 347-366. Abacus Press, Tunbridge Wells, Kent, UK. ISBN 0856260185.

Legett, J. A., Peebles, R. W., Patoch, J. W. and Reinemann, D. J. 1997. USDA DMRY forage research center milking system improvements. Paper No. 973037. Presented at the ASAE Annual International Meeting, Minneapolis Convention Center, Minneapolis, Minnesota, 10-14 August, 1997. Available at: http://www.uwex.edu/uwmril/pdf/RuralEnergyIssues/ Dairy/ASAE_973037_USDA_Energy.pdf.

AQ6

Longmore, A. P. 1973. The pros and cons of vacuum cooling. Food Industries of South Africa, 6-11 May.

Mattarolo, L. 1990. Refrigeration and food processing to ensure the nutrition of the growing world population. Progress in the science and technology of refrigeration in food engineering. In: Proceedings of meetings of commissions B2, C2, D1, D2D3: 43-54, 24-28 September 1990, Dresden, Germany, Institut International du Froid, Paris, France. ISBN 2-903-633-533.

Miles, C. A., van Beek, G. and Veerkamp, C. H. 1983. Calculation of thermophysical properties of foods. In: Physical Properties of Foods: 269-312. Applied Science Publishers, New York.

AQ7

Milk Development Council. 1995. Bulk milk tanking cooling efficiency. Project No. 95/R1/19 report.

Myers, M. 1981. Planning and engineering data. 1. Fresh fish handling. FAO Fisheries Circular No. 735.64 p. Food and Agri- culture Organization of the United Nations, Rome (Italy). Available at: http://www.fao.org/DOCREP/003/P3407E/P3407E05. HTM.

Plemper, G. S. and Stace, G. 2003. Climate change levy and its application within the dairy industry. International Journal of Dairy Technology 56(2): 68-75.

Robertson, G. H., Cipolletti, J. C., Farkas, D. F. and Secor, G. E. 1976. Methodology for direct contact freezing of vegetables in aqueous freezing media. Journal of Food Science 41: 845-851.

Souness, M. 2005. Good housekeeping saves energy. Available at: http://www.mercuryenergy.co.nz/Farming/news_story.aspx?id= 362.

Swain, M. J. 2006. Improving the energy efficiency of food refrigeration operations. IChemE Food and Drink Newsletter, 4 September 2006.

Zerbini, P. E. 1990. Chilling of Top and Citrus Fruit. In: Zeuthen, et al., editor, Processing and Quality of Foods. Volume 3. Chilled Foods: The Revolution in Freshness: 3.336-3.355. Elsevier Applied Science Publishers, London, UK.

Zugarramurdi, A., Parin, M. A. and Lupin, H. M. 1995. Economic engineering applied to the fishery industry. FAO Fisheries Technical Paper T351: 64 p. Food and Agriculture Organization of the United Nations, Rome, Italy. ISBN 92-5103738-8.

\section{About the corresponding author}

Mark J. Swain, Food Refrigeration and Process Engineering Research Centre (FRPERC), University of Bristol, Churchill Building, Langford, North Somerset, BS40 5DU, UK. Phone; +44(0)117938 9310, Fax: +44 (0)117928 9314,Email:m.j.swain@bristol.ac.uk.

For over 33 years Mark Swain has been carrying out studies on all aspects of food refrigeration, initially at the AFRC Meat Research Institute (MRI) then the Institute of Food Research - Bristol Laboratory (IFR-BL) and since 1991 at FRPERC. This work covers the whole cold chain from primary chilling through storage, transport and distribution to domestic handling. He has also worked extensively on thermal processing of food especially on the industrial, commercial and domestic use of microwaves. He has over 100 publications and a wide experience in commercial consultancy work. 